\title{
COnE).(OES
}

CIÊNCIA E TECNOLOGIA

A INSERÇÃO DA MÚSICA COMO RECURSO DIDÁTICO-PEDAGÓGICO PARA O ENSINO DE QUÍMICA

\section{A INSERÇÃO DA MÚSICA COMO RECURSO DIDÁTICO-PEDAGÓGICO PARA O ENSINO DE QUÍMICA}

Valdecir Manoel da Silva ${ }^{1}$, Francisco Ferreira Dantas Filho $^{1}$, Gilberlândio Nunes da Silva $^{1}$

${ }^{1}$ Universidade Estadual da Paraiba

$<$ valdecir.kelvin@hotmail.com> $\mid<$ dantasquimica@yahoo.com.br> $<$ gil.gilberlandionunes@gmail.com>

DOI: <https://doi.org/10.21439/conexoes.v14i4.1541>

Resumo. Este trabalho foi desenvolvido com o propósito de avaliar se a inserção da música como recurso-pedagógico favorece o desempenho dos alunos na aprendizagem do conteúdo Introdução ao estudo da Química. A proposta de ensino elaborada objetivou contribuir com o ensino deste conteúdo, minimizando dificuldades de aprendizagem dos alunos e buscando despertar o interesse e a motivação para aprender. A inserção da música nas atividades pedagógicas, estimula a participação dos alunos nas aulas de Química, propiciando a aprendizagem dos conceitos científicos associados ao conteúdo e rompe com a prática do ensino tradicional que, na maioria das vezes é por meio de aulas expositivas. A pesquisa tem natureza qualitativa com abordagem interpretativista. Os sujeitos desta pesquisa foram 81 estudantes do $1^{\circ}$ ano do Ensino Médio. O Instrumento de coleta de dados foi um questionário semiestruturado contendo 10 questões. Os resultados apontam que o uso da música como recurso didático-pedagógico auxilia os docentes e propicia aos educandos aulas mais prazerosas, despertando-lhe o interesse pela disciplina, tornando as aulas diversificadas e motivadoras, nas quais os educandos interagiram mais entre si e com o professor. Portanto, a proposta de ensino compreendendo a música como recurso didático favorece o processo de ensino-aprendizagem do conteúdo científico ensinado nas aulas de Química na Educação Básica.

Palavras-chaves: Ensino de Química, Música, Aprendizagem.

Abstract. This work was developed with the purpose of evaluating whether the insertion of music as a pedagogical resource favors students' performance in learning the topic Introduction to the study of Chemistry. The elaborated teaching proposal aimed to contribute to the teaching of this topic, minimizing learning difficulties of the students and seeking to arouse interest and motivation to learn. The insertion of music in pedagogical activities stimulates the participation of students in Chemistry classes, facilitating the learning of the scientific concepts associated with the topic and breaks with the traditional teaching practice, which is most often through expository lectures. The research has a qualitative nature with an interpretative approach. The subjects of this research were 81 students from the 1st year of High School. The instrument of data collection was a semi-structured questionnaire containing 10 questions. The results point that the use of music as a didactic-pedagogical resource assists the teachers and gives the students more pleasant classes, arousing their interest in the subject, making the classes diversified and motivating, in that classes the students interacted more with each other and with the teacher. Therefore, the teaching proposal comprising music as a didactic resource favors the teaching-learning process of the scientific content taught in Chemistry classes in Basic Education.

Keywords: Teaching Chemistry, Music, Learning. 


\section{INTRODUÇÃO}

A música está presente em todos os setores do cotidiano proporcionando aos alunos estarem frequentemente em contato com ela e consequentemente apreciá-la. Sabedor desse potencial, o professor ao apropriar-se deste recurso pode inovar sua prática e aproximar os discentes dos conteúdos escolares vivenciados em sua sala de aulas. Silveira e Kiouranis (2008, p.28), afirmam que “a utilização da música no Ensino da Química pode ser uma alternativa importante para estreitar o diálogo entre saberes cotidianos e conhecimento científico". A procura por métodos inovadores para a diversificação das aulas torna-se cada vez mais necessário para conquistar a atenção dos estudantes que são, cotidianamente, atraídos por variados recursos e aparelhos tecnológicos. O professor não conseguindo acompanhar este avanço tecnológico na mesma velocidade que os nativos digitais, é constantemente desafiado a elaborar, experimentar e aplicar estratégias de ensino para minimizar dificuldades apresentadas pelos educandos. Ao aplicar o recurso didático-pedagógico da música no ensino de Química, fica evidente o encantamento e o prazer gerado nos educandos durante as aulas, além de facilitar a assimilação e despertar os alunos quanto ao aprofundamento dos conceitos vinculados aos conteúdos trabalhados em sala de aula.

\section{Referencial Teórico}

\subsection{O Ensino de Química}

Quando se lê ou se discute sobre o ensino e aprendizagem de Química no Ensino Médio, fica evidente a ênfase que se dá à falta de compreensão dos alunos em relação aos conteúdos desta disciplina. O problema desencadeia uma série de discussões em busca dos fatores que causam esta dificuldade.

\begin{abstract}
[...] o ensino de Química transformou-se em preocupação premente nos últimos anos, tendo em vista que hoje além das dificuldades apresentadas pelos alunos em aprender Química, muitos não sabem o motivo pelo qual estudam esta disciplina, visto que nem sempre esse conhecimento é transmitido de maneira que o aluno possa entender a sua importância. (BITENCOURT et al. 2015)
\end{abstract}

Estratégias de ensino, tais como, a contextualização, interdisciplinaridade e o uso de recursos didáticos não repetitivos podem contribuir para minimizar as dificuldades que acompanham o processo de ensinoaprendizagem. Porém, é importante destacar que, o professor é o principal responsável pela criação de meios ou alternativas didáticas que minimizem os efeitos negativos causados pelas séries anteriores e repas- sados por intermédio de um ensino obsoleto não condizente com a prática docente desenvolvida na atualidade. Nos documentos PCNEM, a contextualização é expressa como mecanismo por meio do qual se procura dar uma nova significação ao conhecimento escolar, viabilizando ao aluno uma aprendizagem mais significativa (BRASIL, 1999).

O professor ao se deparar com tais desafios necessita adotar uma postura diferente da conhecida "tradicional". Maldaner e Piedade (1995, p. 15) relatam "o efeito positivo de uma nova postura dos professores frente à química que se ensina nas escolas, rompendo, em especial no primeiro ano do ensino médio, com os esquemas tradicionais". O ensino de Química alia-se ao conhecimento presente no cotidiano das pessoas, devendo ser contextualizado e significativo para quem está aprendendo.

\subsection{Onsino nas escolas públicas}

Segundo os trabalhos reportados na literatura científica, a escola pública tem enfrentado nas últimas décadas problemas relacionados aos índices dos órgãos de avaliação educacional, entre eles, quando comparados às instituições particulares. Segundo Demo (2007. p. 181) "a distância entre escola pública e particular no Brasil é considerável, em favor da escola particular”. A diferença maior possivelmente é que a escola particular é gerida pela iniciativa privada com base na pressão do mercado e dos pais dos alunos, do que segue que seu desempenho, mesmo não sendo aceitável, é mais elevado (DEMO, 2007, p. 181). No entanto, é importante destacar que a escola pública atende a maioria dos estudantes brasileiros, principalmente os pertencentes a classe social baixa e média que na maioria das vezes só pode contar com ela.

Afinal, se o ensino é ruim as aulas são ruins e isto recai sobre os professores. Gadotti (2003, p. 40), afirma: "nenhum país do mundo se desenvolveu sem uma boa escola pública. Nenhuma sociedade se desenvolveu sem incorporar a maioria dos seus cidadãos ao bem viver". Despertar o prazer para aprender não é tarefa fácil, mas exige esforço, pesquisa, tempo e principalmente vontade. Neste aspecto, o mesmo autor defende que "o aluno só aprenderá quando tiver um projeto de vida e sentir prazer no que está aprendendo", portanto, a escola e o professor têm participação fundamental na construção desse projeto de vida, principalmente nos dias atuais quando a família enfrenta um processo de reconfiguração socioafetiva. 


\subsection{A aula criativa}

A aula sempre foi considerada como cerne do ofício do professor, bastava expor o conhecimento dos conteúdos para ministrar aulas e passar exercícios, sendo assim, durante muito tempo. Atualmente há uma necessidade de modificar esta prática de ensino, pois a tecnologia e a quantidade de informações do mundo externo aos muros da escola provocaram mudanças significativas rapidamente em toda sociedade. A sala de aula apresenta uma constituição heterogênea e, quando se aplica sempre o mesmo tipo de recurso didático, perpetua-se um modelo padronizado considerando que todos aprendem de igual maneira. No entanto, para muitos alunos, assistir aulas e fazer exercícios não é suficiente para aprender.

Segundo Perrenoud (2000, p. 24), "só aprendem verdadeiramente, por meio dessa pedagogia, "os herdeiros", aqueles que dispõem dos meios culturais para tirar proveito de uma formação que se dirige formalmente a todos". Portanto, há uma necessidade de se elaborar alternativas gerando situações para que os alunos que, não aprendem somente com exercícios, possam aprender através de outras metodologias. Nem sempre a aplicação destas alternativas ou situações servirá para todos, pois um professor experiente sabe que as atividades que cria, por mais bem concebidas e preparadas que sejam, nem sempre dão os resultados esperados. No entanto, é importante adotar outros recursos por servirem como portadores de regulação em situações de aprendizagem, pois como afirma Perrenoud (2000, p. 51) no ambiente escolar "convém que o professor aposte em tecnologia e dispositivos didáticos interativos, portadores de regulação".

\subsection{Desafios do professor}

Atualmente, o trabalho docente enfrenta os desafios da comunicação tecnológica, pois os estudantes convivem com variedades de informações ao manusearem, cada vez mais, diferentes meios tecnológicos transmissores de mensagens disseminadas nos meios da comunicação social. Estes meios comunicacionais concorrem com os suportes que veiculam os conteúdos escolares, na maioria das vezes, apenas o livro didático, cuja realidade compete com a comunicação escolarizada.

O professor da atual escola não deve ser aquele que, apenas domina os saberes a serem ensinados, que tenha o controle da turma e faça avaliações. Atualmente é exigido muito mais para o ofício de professor. Conforme Perrenoud (2000, p. 13), o ofício de professor deve "envolver os alunos em suas aprendizagens e em seu trabalho", pois o envolvimento dos educandos no processo ensino-aprendizagem é, também, responsabilidade do professor.

Quando uma aula está sendo ministrada, como saber o que está processando a cabeça do estudante com as informações adquiridas? ou seja, como ocorrem as situações de aprendizagem? O professor deve compreender que estas situações não podem ser padronizadas, pois numa sala de aula as diferenças cognitivas são nítidas, então, um único método não resulta em um mesmo resultado. Perrenoud (2000, p. 24), afirma em relação aos professores que, "enquanto praticarem uma pedagogia magistral e pouco diferenciada, não dominarão verdadeiramente as situações de aprendizagem nas quais colocam cada um de seus alunos". Portanto, é preciso que haja uma preocupação com aqueles cuja aula expositiva com a realização de exercícios não é suficiente para aprender.

\subsection{Motivação para ensinar e aprender}

Muitos professores sabem que é preciso encontrar meios de estimular seus alunos para aprender, porém, não é fácil. Para motivar é preciso estar motivado e a alegria de ensinar é um tempero essencial para o despertamento dos alunos. Gadotti (2003, p, 49) afirma que "só aprendemos quando colocamos emoção no que aprendemos. Por isso é necessário ensinar com alegria". O desencanto dos alunos pelas aulas de Química é fruto, muitas vezes, de aulas sem emoção e sem alegria. Estar na frente de uma TV é mais prazeroso que diante de uma aula em que o professor transmite conteúdos descontextualizados e distantes do cotidiano dos alunos.

É inegável que os jovens vivem num mundo de desencanto e agressividade crescente, mas, o professor precisa administrar estes embaraços e desdobrar-se na busca por promover o reencontro dos educandos com a escola e o aprendizado do conteúdo escolar. Segundo Gadotti (2003, p. 55), “o novo profissional da educação é também um profissional que domina arte de reencantar, de despertar nas pessoas a capacidade de engajar-se e mudar". Neste sentido, Alves (2004, p. 13), afirma que "é fácil obrigar o aluno a ir à escola. O difícil é convencê-lo a aprender aquilo que ele não quer aprender". Esta afirmação retrata uma escola engessada que segui um programa imposto pelo sistema de ensino nacional, incentivado por modelos de ingresso ao ensino superior que, cobra dos alunos conteúdos sem sentido e distantes da sua vida cotidiana, muitos deles, sem utilização na carreira acadêmica, visando apenas o ingresso na universidade. 
Para que o bloqueio deste sistema de programas enrijecido e inflexível seja rompido, o professor deverá superar-se na diversificação das aulas e apegar-se a experiências afetivas. Toda experiência de aprendizagem se inicia com uma experiência afetiva (ALVES, 2004 p. 21). A afetividade vem sendo percebida como um meio de despertar o interesse pela aprendizagem. Não se trata das práticas correntes de abraços e beijinhos entre professores e alunos, essa afetividade se revela quando o professor tem prazer de ensinar, quando se dedica a sua prática, pensa nos seus alunos e na realização dos seus sonhos.

Quando o professor utiliza o afeto como meio para conquistar seus alunos, os mesmos procuram aprender não porque gostam, mas por gostar do professor. Se o aluno é conquistado pelo afeto, estará mais disponível ao aprendizado e sentirá mais prazer em aprender. Portanto, o afeto desenvolvido pelo professor é fundamental para quem aprende conforme Alves (2004, p. 35) "[...] frequentemente se aprende uma coisa de que não se gosta por se gostar da pessoa que a ensina".

\subsection{A música no cotidiano escolar}

Vivemos numa sociedade completamente cercada pela música e o cotidiano escolar não é diferente. Conforme Loureiro (2001, p. 18), “[...] a música está presente no cotidiano escolar de nossas crianças e jovens. Ela está presente em todo e qualquer lugar, pois vem ocupando cada vez mais espaços no cenário social da vida contemporânea". O trabalho com música nas aulas de química, não deve ser visto como um acessório de entretenimento quando as aulas se tornarem repetitivas e desmotivadoras. A música deve ser utilizada como recurso didático-pedagógico que contribui para o desenvolvimento do ensino aprendizado do aluno, além de constituir-se em uma prática prazerosa que dinamiza a aula.

A utilização da música nas aulas de Química contribui significativamente por ser um recurso pedagógico simples, de baixo custo que oportuniza ao aluno estabelecer relações interdisciplinares com os conteúdos escolares. é uma atividade lúdica que transpõe algumas barreiras da educação formal, podendo ser utilizada como atividade cultural. Este recurso tem sido utilizado com frequência na educação escolar, pois consegue aliar aspectos lúdicos e cognitivos. Desta maneira,

apesar da música não ilustrar visualmente o conteúdo que pode explorado, ela se constitui como um veículo de expressão que é capaz de aproximar mais o aluno do tema a ser estudado. Aproveitando-se da facilidade com que a música é assimilada pelas pessoas, pode-se fazer uso desse recurso, associando-o com o conteúdo disciplinar, de forma prazerosa (BARROS; ZANELLA; ARAÚJOJORGE 2013 p. 82).

Ao se utilizar este recurso, o docente deve entender que, a música por si só não contempla todo conteúdo, é uma maneira de atrair os alunos e fazê-los gostar de química, quando para a maioria, a química não tem atrativo nenhum, por ser considerada como uma disciplina difícil de aprender e muito chata. As escolas passam por transformações constantes, por isso, é fundamental a busca pela reformulação dos métodos de ensino. As práticas devem ser constantemente mudadas, repensadas, recriadas e diversificadas para que o aluno seja atraído. Todo esse dinamismo que gira em torno da escola contemporânea faz recair sobre o professor uma gigantesca responsabilidade, pois, o mesmo, além de se preocupar com a tecnologia, que é crescente nas escolas, e veio para ficar, precisa estar cotidianamente pesquisando e encontrando meios para diversificar sua prática.

\subsection{Música como recurso-didático potencializador da aprendizagem}

Toda sociedade apresenta um gosto pela música manifestada na cultura através de rituais, cerimoniais, aproximação do sagrado e outros. Na sociedade contemporânea a música se afirma como essencial, estando presente nos cultos religiosos, nas propagandas midiáticas, nas festas, nos lares e nas escolas, podendo ser utilizada como recurso-didático pedagógico com excelente poder atrativo e motivador, como afirmam Cunha e Pacheco (2011, p. 332), "a música como um meio, expressa dimensões cognitivas, emocionais, sociais, potencializa processos subjetivos. A música como um fim, encanta, embeleza, dá sentido ao dia a dia".

Nas civilizações antigas a música era venerada e utilizada como meio de transmissão de ordens divinas e de gratidão às benevolências concedidas pelas divindades. Os grandes filósofos também tinham na música uma fonte de "poder". Platão foi enfático ao anunciar que "a música é a parte fundamental da educação". A música é fascinante e contagiante, é difícil encontrar pessoas que não sejam envolvidas pelos sons e canções dos gêneros mais variados possíveis. Muitas civilizações tinham a música como algo mágico. Aristóteles recomendou a música como componente crucial de uma educação liberal (BLANNING, 2011, p. 24).

Percebe-se a fluência da música no cotidiano das pessoas e a facilidade de como elas aprendem as músicas tocadas nos meios midiáticos como a exemplo rádio, TV, internet e outros. Seja pela repetição, ou não, 
é facilmente perceptível que uma informação é assimilada mais rapidamente quando é associada a música. Sendo assim, pode-se utilizar o recurso da música como atrativo nas aulas de química, pois é uma alternativa que interliga saberes do cotidiano e conhecimentos científicos. Para Silveira e Kiouranis (2008, p. 29) “a música e a letra podem ser uma alternativa importante para estreitar o diálogo entre alunos, professores e conhecimento científico, uma vez que abordam temáticas com grande potencial de problematização e está presente de forma significativa na vida do aluno".

Os saberes do cotidiano aparecem na mídia com bastante frequência, é comum ouvir sobre aquecimento global, poluição atmosférica, derramamento de petróleo no mar, contaminação dos rios pelos esgotos caseiros ou industriais, etc. Ao trabalhar essas temáticas, geralmente, a química é tida como a grande vilã, responsável por vários problemas como doenças, poluição, contaminação e drogas. Portanto, é necessário desmistificar este pensar e procurar por meio do conhecimento científico mostrar o outro lado da moeda, ou seja, a fundamental importância da química na transformação e obtenção de materiais para o bem-estar da humanidade. Por isso, "o conhecimento químico pode ser construído pelas crianças e pelos jovens de tal forma que eles compreendam questões relevantes e outras tangíveis ao dia a dia, assim como possam contribuir para modificar a imagem sobre a Química" (SILVEIRA; KIOURANIS, 2008, p. 28).

Em meio a tanta tecnologia os professores encontram dificuldades em despertar o interesse dos alunos pelas aulas, quando se trata de química, fica ainda mais complicado. Neste sentido, a procura de recursos para atrair o interesse do aluno é uma tarefa estressante para o professor compromissado com sua prática. Ao falar da música como recurso em sala de aula, Silveira e Kiouranis (2008, p. 29), afirmam que "a música pode auxiliar no ensino de uma determinada disciplina, na medida em que, ela abre possibilidades para um segundo caminho que não é o verbal". De fato, a música tem uma potencialidade enorme, e quando a aula é planejada adequadamente, torna-se um excelente recurso favorecendo o ensino e aprendizagem do conteúdo de Química.

É bom salientar que a música desperta o interesse pela disciplina, mas é um fenômeno momentâneo e corre-se o risco de enfatizar apenas a memorização de conceitos e fórmulas. Com isso o trabalho termina corroborando com o ensino tradicional que tanto se critica. Assim, é preciso ter cuidado quando utilizar música na aula para não a limitar somente como instrumento de memorização, pois, dessa maneira, ela perde seu poten- cial de contextualização e enfatizará apenas a euforia do momento. Conforme Silveira e Kiouranis (2008, p. 30), “[...] a música pode ser utilizada para contextualizar o ensino, dando maior significado aos conceitos ou conhecimentos por ela veiculados".

A discussão e o aprofundamento do contexto musical no ensino escolar são fundamentais para intensificar o aprendizado e construir conhecimentos com significação própria do conteúdo trabalhado pela química. Ainda segundo Silveira e Kiouranis (2008, p.30), "uma aula de química poderia começar de maneira lúdica, procurando estimular os alunos com a música. Para além desse estímulo, estão as relações que podem ser estabelecidas entre a química como saber ensinado e a letra da música". Ao fazer desta maneira o docente estará diversificando sua prática e contribuindo para uma maior aproximação entre ele e seus alunos.

\section{Metodologia}

As observações descritas nesta pesquisa se construíram com base na abordagem de análise interpretativista que consiste de um conjunto de métodos e práticas empregados na pesquisa qualitativa, a saber: observação participante, estudo de caso, interacionismo simbólico, pesquisa fenomenológica e construtivista, entre outros (BORTONI-RICARDO, 2008, p. 33).

A pesquisa qualitativa com abordagem interpretativa propicia um caminho subjetivo, construído a partir das representações sociais desenvolvidas pelos sujeitos e entre os sujeitos. Os métodos qualitativos destacam a flexibilidade como uma característica indispensável, principalmente quanto às técnicas de coleta de dados, incorporando aquelas mais adequadas à observação que está sendo feita (MARTINS, 2004, p. 292).

O público alvo foi constituído por 81 alunos do $1^{\circ}$ ano de uma Escola Estadual de Ensino Fundamental e Médio da cidade de Natuba - PB. Para coleta de dados foi aplicado um questionário semiestruturado contendo 10 questões objetivas com a finalidade de avaliar a importância e satisfação dos estudantes em relação ao uso da música no processo de ensino e aprendizagem dos conceitos científicos trabalhados na proposta.

\subsection{Descrição da Proposta Didático-pedagógica}

A proposta é composta de ações procedimentais compreendendo indagações iniciais visando verificar conhecimentos prévios dos educandos em relação importância da química.

A proposta traz a música Ciência que estuda os materiais como recurso didático para ensinar o conteúdo 
Introdução ao estudo da Química em turmas do $1^{\circ}$ ano do Ensino Médio de maneira diversificada e dinâmica.

O planejamento das aulas para o ensino do conteúdo de Química, inseriu o lúdico como recurso didáticopedagógico auxiliar com a intenção de motivar os alunos a estudarem Química e vislumbrarem de forma transversal esta ciência no seu cotidiano. A proposta didática foi elaborada para ser executada em 6 aulas com duração de 45 minutos, conforme demonstra o Quadro 1 abordando a música intitulada "Ciência que estuda os materiais", cuja letra colabora para ensinar o conteúdo Introdução ao estudo da Química relacionando-o com o cotidiano dos educandos.

\section{CIÊNCIA QUE ESTUDA OS MATERIAIS}

Música: Valdecir Manoel da Silvę

Química ciência que estuda os materiais suas transformações e a energia envolvida na preparação de novas produções.

Tudo começou quando o homem conseguiu acender o fogo pela primeira vez, a partir daí ele logo descobriu que a vida poderia melhorar de vez, que da natureza poderia retirar o que necessitava para sua vida melhorar.

Usavam metais, cerâmica, vidro, perfumes contidos nos vegetais, destilação, fermentação, conservação, os alimentos já não se perdiam mais e apesar de tudo não sabiam como explicar faltavam métodos e teorias era tudo prática.

No século XVII Robert Boyle estabeleceu uma ligação para interpretação de fatos que a alquimia não dava explicação. No século XVIII Lavoisier, pesou e mediu para reconhecer:

Na natureza não se cria, não se perde, tudo se transforma $\mathrm{E}$ todo esse conhecimento conseguiu abrir o caminho para outros que vieram a seguir e que fizeram essa grande ciência que estudamos hoje aqui.

Após apresentar e cantar com os alunos a música "Ciência que estuda os materiais", foi realizada uma discussão a acerca das estrofes e sua relação com os conceitos da Química abordados nos livros didáticos e durante as aulas expositivas para reforçar a aprendizagem dos conteúdos inseridos nas estrofes que foram destacadas, interpretadas e debatidas pelos estudantes.

\footnotetext{
${ }^{1}$ Autor da Pesquisa
}

\subsection{Levantamentos de concepções prévias}

Na primeira etapa da aplicação da música, os alunos foram convidados a refletirem sobre a importância da Química e sua história por meio de uma exposição dialogada verificando o conhecimento prévio dos educandos como análise inicial. Em seguida foi realizada a distribuição das estrofes da música em recortes para leitura e abordagem dos conteúdos relacionados em cada estrofe. Posteriormente os educandos convidados a cantarem a música acompanhada pelo violão. Após cantoria da música os educandos assistiram a um vídeo e leram um texto para aprofundamento nas discussões e logo em seguida realizaram um teste com dez questões sobre conteúdo Introdução ao estudo da Química para verificação da aprendizagem. Utilizou-se essa música como recurso, a fim de propiciar ao aluno associar os conceitos de química utilizados no decurso das aulas. Após a apresentação e execução da proposta de ensino, aplicou-se um questionário com o objetivo de colher informações sobre o percurso metodológico utilizado durante a execução da proposta.

\section{Resultados e Discussão}

O instrumento utilizado para coleta de dados buscou respostas relacionadas ao: Perfil dos discentes; avaliação da proposta de ensino sob o ponto de vista pedagógico e, avaliação da metodologia aplicada durante a execução da proposta.

Traçando o perfil dos participantes, evidenciou-se a predominância do sexo feminino representada por $75,3 \%$, enquanto que o masculino atingiu o percentual de $24,7 \%$. Quanto à faixa etária, os participantes estão agrupados entre 14 a 21 anos. Nas duas turmas, o percentual de alunos com idade acima de 18 anos é $8,6 \%$; entre 16 e 17 anos $24,7 \%$ e; entre 14 e 15 anos $66,7 \%$. Percebe-se que a maioria se encontra na faixa etária adequada para cursar o primeiro ano do Ensino Médio.

\subsection{Avaliação da proposta de ensino pelos sujeitos da pesquisa}

Para a avaliação da proposta de ensino foram realizados os seguintes questionamentos: 1) A abordagem de conteúdos de química através da música contribui com a aprendizagem? 2) A proposta didática apresenta características significativas para ensinar de forma contextualizada? Na sistematização dos resultados, a maioria dos sujeitos pesquisados concordam que a abordagem de conteúdos de química através da música, contribui 
A INSERÇÃO DA MÚSICA COMO RECURSO DIDÁTICO-PEDAGÓGICO PARA O ENSINO DE QUÍMICA

Quadro 1: Descrição procedimental da proposta didática para o conteúdo "Introdução ao estudo da Química"

\begin{tabular}{|c|c|c|c|}
\hline AULA/TEMPO & $\begin{array}{l}\text { ATIVIDADES } \\
\text { REALIZADAS }\end{array}$ & $\begin{array}{c}\text { RECURSOS } \\
\text { METODOLÓGICOS } \\
\end{array}$ & $\begin{array}{c}\text { OBJETIVOS } \\
\text { PROCEDIMENTAIS } \\
\end{array}$ \\
\hline $\begin{array}{c}\text { Aula 1: } \\
\text { Introdução ao } \\
\text { estudo da Química. } \\
\text { Tempo: } 45 \mathrm{~min} . \\
\end{array}$ & Exposição do conteúdo. & $\begin{array}{l}\text { Indagações realizadas } \\
\text { oralmente pelo docente. }\end{array}$ & $\begin{array}{l}\text { Verificar o conhecimento } \\
\text { prévio dos educandos em } \\
\text { relação ao estudo da Química } \\
\text { e sua história. }\end{array}$ \\
\hline $\begin{array}{l}\text { Aula 2: } \\
\text { Texto Musical. } \\
\text { Tempo: 45min. }\end{array}$ & $\begin{array}{l}\text { Distribuição das estrofes da música } \\
\text { em recortes, leitura e abordagem } \\
\text { inicial do conhecimento prévio dos } \\
\text { educandos sobre História da Química. }\end{array}$ & $\begin{array}{c}\text { Utilização da oralidade } \\
\text { e argumentação dos estudantes } \\
\text { instigadas por questões inicialmente } \\
\text { realizadas pelo professor. }\end{array}$ & $\begin{array}{l}\text { Discutir sobre a História da Química } \\
\text { e as contribuições na sociedade ao } \\
\text { longo de sua evolução como ciência. }\end{array}$ \\
\hline $\begin{array}{c}\text { Aula 3: } \\
\text { Música } \\
\text { Tempo: 45min. }\end{array}$ & $\begin{array}{l}\text { A música "Ciência que estuda os materiais", } \\
\text { inicialmente cantada pelo professor, } \\
\text { seguida pelos alunos. }\end{array}$ & $\begin{array}{c}\text { Uso do instrumento musical (violão), } \\
\text { letra da música digitalizada, impressa } \\
\text { contendo questões relacionadas ao } \\
\text { conteúdo em cada estrofe. }\end{array}$ & $\begin{array}{l}\text { Despertar o interesse dos educandos } \\
\text { pelo estudo da Química de } \\
\text { maneira divertida. }\end{array}$ \\
\hline $\begin{array}{l}\text { Aula 4: } \\
\text { História da Química. } \\
\text { Tempo: 45min. }\end{array}$ & $\begin{array}{c}\text { Leitura e discussão do texto: } \\
\text { Da alquimia à Química. } \\
\text { (Livro Química Cidadã dos autores } \\
\text { Wildson Luiz Pereira dos Santos e } \\
\text { Gerson de Souza Mól, editora AJS Ltda, 2013). }\end{array}$ & $\begin{array}{c}\text { Utilização da oralidade e argumentação } \\
\text { dos estudantes instigadas nas reflexões } \\
\text { estendidas pelo professor. }\end{array}$ & $\begin{array}{l}\text { Discutir sobre a histórica da Química } \\
\text { e as contribuições dos cientistas para o } \\
\text { desenvolvimento desta ciência. }\end{array}$ \\
\hline $\begin{array}{c}\text { Aula 5: } \\
\text { Vídeo. } \\
\text { Tempo: 45min. }\end{array}$ & $\begin{array}{l}\text { Apresentação do vídeo: } \\
\text { O que é a Química. }\end{array}$ & $\begin{array}{l}\text { Utilização do computador, } \\
\text { projetor multimídia e caixa acústica. }\end{array}$ & $\begin{array}{l}\text { Diversificar a aula para o conteúdo } \\
\text { Introdução ao estudo da Química }\end{array}$ \\
\hline $\begin{array}{l}\text { Aula 6: } \\
\text { Verificação da } \\
\text { aprendizagem. } \\
\text { Tempo: } 45 \mathrm{~min} .\end{array}$ & $\begin{array}{l}\text { Realização de um teste com dez } \\
\text { questões sobre conteúdo } \\
\text { Introdução ao estudo da Química. }\end{array}$ & $\begin{array}{l}\text { Aplicação de teste digitalizado e impresso } \\
\text { contendo } 6 \text { questões fechadas e } 4 \text { abertas } \\
\text { sobre Introdução ao estudo da Química. }\end{array}$ & $\begin{array}{l}\text { Verificar o desempenho do educando } \\
\text { na aprendizagem do conteúdo } \\
\text { Introdução ao estudo da Química. }\end{array}$ \\
\hline
\end{tabular}

Fonte: Autores (2017)

facilitando a aprendizagem. Antes de apresentar a proposta de ensino com a inserção da música, foi indagado aos sujeitos da pesquisa: é possível aprender Química utilizando a música? Na Figura 1 estão expressos os resultados sistematizados.

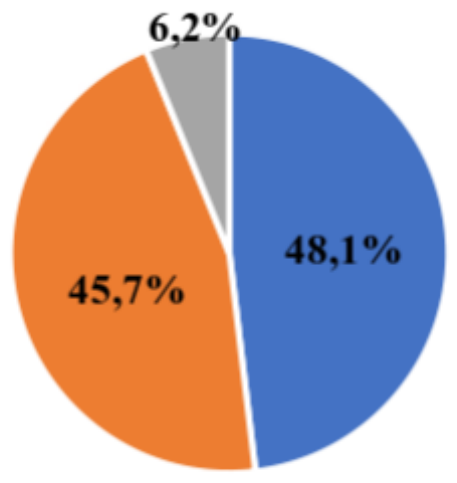

\section{Sim Não Não responderam}

Figura 1: Opiniões dos participantes sobre a possibilidade de aprender Química com inserção da música.

Fonte: Autores da pesquisa.

Através dos percentuais apresentados na Figura 1, percebe-se que $48,1 \%$ dos entrevistados responderam que "não compreenderam" como se daria esta prática, pois nunca haviam vivenciado uma experiência como esta; 45,7\% responderam "Sim", justificaram dizendo ser uma maneira diferente e divertida que facilita desperta mais o interesse pela disciplina. Apenas 6,2\% dos entrevistados não responderam.

Após a aplicação da proposta de ensino, os pesquisados foram convidados a responder a seguinte pergunta: é fácil compreender os conceitos de Química? Os resultados obtidos estão expressos na Figura 2.

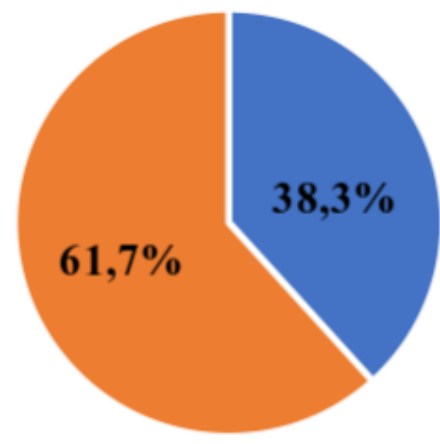

- Sim " Não

Figura 2: Respostas dos participantes acerca da compreensão dos conceitos de Química.

Fonte: Autores da pesquisa.

A Figura 2, mostra que $61,7 \%$ dos entrevistados responderam que não é fácil entender os conceitos perti- 
nentes à disciplina Química, 38,3\% afirmaram "Sim". As justificativas foram variadas. Muitos disseram depender do professor, alguns alegaram ter problemas com os cálculos; outros disseram não sentir tanta dificuldade e que o professor contribuía para isso. Os que responderam "Sim" disseram que gostavam da matéria, que o professor explica bem e haver conteúdos mais fáceis de aprender.

Os dados alertam para a importância de conquistar a simpatia dos estudantes e motivá-los para gostar de Química, cientificando-os sobre a importância dos conteúdos ensinados para o desenvolvimento do ser como cidadão, pois o Ensino Médio constitui-se numa etapa final para a construção de um cidadão com condições de realizar seus projetos pessoais (RICARDO, 2003).

O primeiro contato do estudante com os conceitos científicos da disciplina Química ocorre no $9^{\circ}$ ano do Ensino Fundamental. Segundo os PCN+ essa disciplina abrange um conjunto de saberes importantes para consolidação do conhecimento científico desta ciência.

O processo de ensino e aprendizagem dos conceitos científicos é abordado em diferentes níveis de complexidade. No entanto, a literatura científica reporta que as abordagens pedagógicas no processo de ensino dos conceitos de Química, estão desvinculadas a realidade dos alunos. Isto contribui para o argumento de que a disciplina os confronta com muito conteúdo e pouco tempo para compreendê-los e absorvê-los (BRASIL, 2002).

Existe um grande desafio das instituições de ensino superior em formar professores que atendam as necessidades da Educação Básica, em especial das componentes de ciências da natureza e matemática. Nesse sentido é importante destacar que os diálogos permanentes entre secretarias de educação, regionais de ensino e cursos de formação continuada de professores poderão contribuir com melhorias na Educação Básica.

Os cursos de formação inicial e continuada têm como objetivo preparar os profissionais da Educação Básica para o exercício da profissão, possibilitando os educandos adquirirem conhecimentos para desenvolverem competências e habilidades que permitirão a estes educadores, sua inclusão de forma ativa e participativa com a sociedade tecnológica e contemporânea em que estão inseridos, atendendo as expectativas dos alunos do século XXI.

São várias as possibilidades que o professor dispõe para diversificar a sua prática, planejando suas aulas com recurso didático que facilite e auxilie na aprendizagem dos conteúdos de Química. Conforme Santos et al. (2013), "as oficinas temáticas atreladas às atividades experimentais e outras estratégias de ensino, contri- buem para despertar o interesse dos alunos em estudar $\mathrm{e}$ aprender Química". Segundo estes autores, "um ensino contextualizado é um agente facilitador para a construção do conhecimento científico, desenvolvimento de habilidades e competências básicas para o exercício da cidadania".

Foi perguntado se a metodologia usada durante a aplicação da proposta contribui para melhorar o desempenho na aprendizagem do conteúdo.

Os resultados obtidos estão expressos na Figura 3.

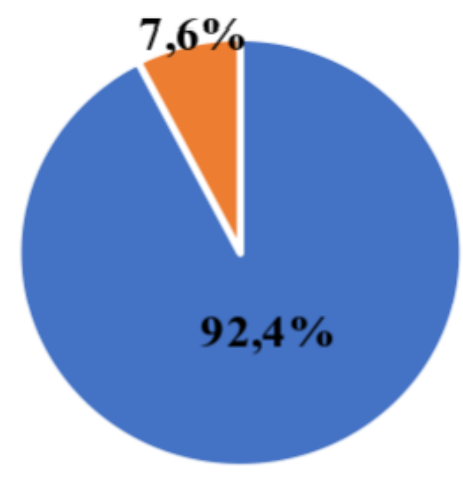

\section{- Sim | Não}

Figura 3: Avaliação dos alunos sobre a metodologia utilizada durante a proposta.

Fonte: Autores da pesquisa.

Conforme os dados da Figura acima, 92,4\% dos alunos afirmam que a metodologia colabora com a aprendizagem dos conteúdos despertando mais o interesse pela disciplina. Relatam que é um método bem diferente e muito legal e que a aula fica mais divertida e dinâmica, muito melhor que a aula tradicional. Apenas 7,6\% responderam não justificando preferir o método tradicional.

$\mathrm{Na}$ perspectiva de Oliveira, Rocha e Francisco (2008, p. 2),

a utilização da música pode ser entendida como uma ati-
vidade lúdica no processo educativo que, além de propor-
cionar o aumento de um conhecimento específico, fun-
ciona como um elemento de aprendizagem cultural que
também estimula a sensibilidade, a reflexão sobre valo-
res, padrões e regras.

O conteúdo ministrado e mediado pelo professor ao fazer uso da música como recurso didático proporcionam aos estudantes interagirem entre si e com o professor fazendo com que os alunos despertem para a importância de aprender Química, e passem a gostar da disciplina percebendo sua importância no cotidiano. 
Os sujeitos foram indagados se a inserção da música nas aulas possibilita a contextualização do conteúdo. Os resultados estão expostos na Figura 4.

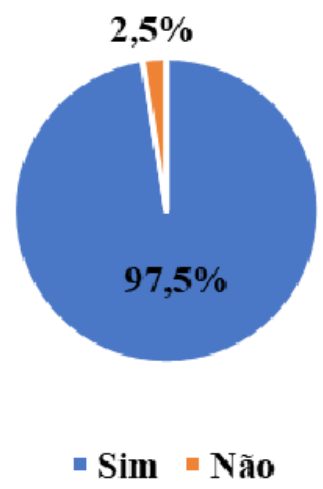

Figura 4: Respostas dos participantes quanto a contextualização do conteúdo com a inserção da música nas aulas.

Fonte: Autores da pesquisa.

A Figura 4 mostra que $92,5 \%$ dos participantes responderam que a proposta de ensino apresenta características significativas que permitem contextualizar conteúdos ensinados com o seu cotidiano e 2,5\% afirmaram que "Não"; e justificaram não compreenderem como pode acontecer tal contextualização. Estes resultados demonstram que a inserção da música nas aulas de Química pode fomentar discussões referentes aos conteúdos ensinados e promover maior interação dos alunos com o professor corroborando para a aprendizagem dos conceitos científicos. Assim, o uso de músicas no Ensino de Química tem sido tema de trabalhos de vários autores, entre eles (BARROS; ZANELLA; ARAÚJOJORGE, 2013), destacando sempre a eficiência em despertar atenção nos alunos. Tal interesse advém da diversão que, muitas vezes, produz efeito positivo na prática cotidiana do professor.

Diversos temas químicos podem ser explorados com o auxílio da música. Portanto, a proposta de ensino com a inserção da música buscou elaborar e implementar nas aulas de química uma abordagem que aproxima química, música e o cotidiano dos educandos, que leva em conta, os pressupostos de estruturação de conteúdo descritos nas Diretrizes Curriculares Nacionais para o Ensino Médio - PCNEM e PCN+. O objetivo principal da proposta didática com a inserção da música foi apresentar aos aprendizes a possibilidade de utilizar a música como recurso didático-pedagógico, não somente para disciplina de química, mas, para qualquer outro componente curricular, bem como divulgar os resultados desta proposta, que posteriormente, poderá ser usada pelos professores do Ensino Médio na sua prática pedagógica para otimizar a aprendizagem do conteúdo científico ensinado. Ao falar de conhecimento científico Santos (2007, p. 478) afirma que, "não se pode pensar no ensino de seus conteúdos de forma neutra, sem que se contextualize o seu caráter social, nem há como discutir a função social do conhecimento científico sem uma compreensão do seu conteúdo".

Os resultados obtidos foram motivadores corroborando com a compreensão de que a inserção da música nas aulas de química é um recurso favorável para despertar o interesse dos educandos no estudo dos conteúdos químicos beneficiando o processo de ensino e aprendizagem. Este pensamento está de acordo com as ideias de Góes (2010, p. 2).

\footnotetext{
Ao inserir-se a música na prática diária do ambiente educativo, a mesma pode tornar-se um importante elemento auxiliador no processo de aprendizagem da escrita e da leitura criando o gosto pelos diversos assuntos estudados, desenvolvendo a coordenação motora - o ritmo, auxiliando na formação de conceitos, no desenvolvimento da autoestima e na interação com o outro.
}

Entende-se que a música proporciona maneiras diversificadas de construir o conhecimento, transformando, pela mediação, a experiência intelectual e afetiva do ser humano, individualmente ou em coletividade; possibilitando ao mesmo interferir, agir mental e ou fisicamente, sob novas formas, pelo acesso a aspectos até então por ele desconhecidos.

Portanto, convém ressaltar que, a utilização da música nas aulas de Química, pode contribuir para uma melhoria no aprendizado do conteúdo Introdução ao estudo da Química e no desempenho dos educandos durante as aulas.

\section{Considerações Finais}

Diante dos resultados obtidos, concluímos que a proposta de ensino com a inserção da música nas aulas de Química, melhorou a interação entre o aluno e o professor, diminuindo a distância entre ambos; motivou e incentivou os alunos a produzirem músicas ou paródias para relacioná-las aos conteúdos estudados na disciplina, facilitando desta forma o seu aprendizado.

Para o professor, o uso da música em suas aulas diversifica a prática docente, tornando-as mais dinâmicas, despertando a atenção dos estudantes, abrindo espaço para a discussão e debate acerca dos conteúdos ensinados. Foi possível observar a alegria dos estudantes ao cantarem as músicas. É oportuno enfatizar que, para se obter o êxito na prática pedagógica com o uso da música 
A INSERÇÃO DA MÚSICA COMO RECURSO DIDÁTICO-PEDAGÓGICO PARA O ENSINO DE QUÍMICA

ou de outros recursos, é necessário ao educador planejar suas aulas utilizando o recurso adequadamente para obter êxito no processo de ensino e aprendizagem.

Enfim, os resultados apontam que a proposta de ensino com a inserção da música contribuiu para o aprendizado do conteúdo Introdução ao estudo da Química, motivando os educandos a gostarem de estudar esta disciplina, demostrando ser uma estratégia de ensino, que pode ser utilizada em sala de aula sem muita dificuldade, além de favorecer ao processo de ensino e aprendizagem.

\section{REFERÊNCIAS}

ALVES, R. O desejo de ensinar e a arte de aprender. 1. ed. Campinas: Fundação Educar Paschoal, 2004.

BARROS, M. D. M.; ZANELLA, P. G.; ARAÚJOJORGE, T. C. de. A música pode ser uma estratégia para o ensino de ciências naturais? analisando concepções de professores da educação básica. Ensaio Pesquisa em Educação em Ciências, v. 15, n. 1, p. 81-94, 2013.

BITENCOURT, H. R.; PINHEIRO, J. C.; MOURA, G. N.; DINIZ, V. W. B.; ALCÂNTARA, I. F.; CUNHA, A.; C., L. M. Fatores que dificultam a aprendizagem do ensino de química dos alunos do $1^{\circ}$ ano de uma escola estadual de breves-pa. In: 14 Encontro de Profissionais de Química da Amazônia (14º EPQA). [S.1.: s.n.], 2015.

BLANNING, T. O triunfo da música: A ascensão dos compositores, dos músicos e de sua arte. 1. ed. São Paulo: Companhia das Letras, 2011. Tradução Ivo Koriyowski.

BORTONI-RICARDO, S. M. O professor pesquisador: Introdução à pesquisa qualitativa. 1 . ed. São Paulo: Parábola Editorial, 2008. v. 2.

BRASIL. Parâmetros Curriculares Nacionais do Ensino Médio. 1. ed. Brasília: MEC; SEMTEC, 1999.

\section{Ensino Médio: Ciências da Natureza,}

Matemática e suas Tecnologias. 1. ed. Brasília: MEC, 2002.

CUNHA, R.; PACHECO, M. C. S. C. A música na vida cotidiana. Revista. Científica, v. 7, n. 1, p. 319-334, 2011.

DEMO, P. Escola pública e escola particular: semelhanças de dois imbróglios educacionais.
Ensaio: avaliação e políticas publicas em educação, Fundação Cesgranrio, v. 15, n. 55, p. 181-206, 2007.

GADOTTI, M. Boniteza de um sonho: ensinar e aprender com sentido. 1. ed. Novo Hamburgo: Feevale, 2003.

GÓES, R. S. A música e suas possibilidades no desenvolvimento da criança. Revista Udesc Virtu@ l, v. 2, n. 1, p. 27-43, 2010.

LOUREIRO, A. M. A. O ensino da química na escola fundamental: um estudo exploratório. Dissertação (Dissertação de Mestrado Apresentada ao Programa de Educação) - PUC/Minas, Belo Horizonte, 2001.

MALDANER, O. A.; PIEDADE, M. C. T. Repensando a química. Química Nova na Escola, v. 1, n. 1, p. 15, 1995.

MARTINS, H. H. T. S. Metodologia qualitativa de pesquisa. Educação e pesquisa, SciELO Brasil, v. 30, n. 2, p. 289-300, maio/ago 2004.

OLIVEIRA, A. D.; ROCHA, D. C.; FRANCISCO, A. C. A ciência cantada: um meio de popularização da ciência e um recurso de aprendizagem no processo educacional. In: Seminário Nacional de Educação Profissional e Tecnológica. Resumos e artigos. Belo Horizonte: CEFET-MG, 2008. v. 1.

PERRENOUD, P. Dez novas competências para ensinar. 1. ed. Porto Alegre: Artes Médicas Sul, 2000. Tradução: Patrícia Chittoni Ramos.

PIAGET, J. A formação do símbolo na criança. 3. ed. Rio de Janeiro: Zahar, 1978.

RICARDO, E. C. Implementação dos pcn em sala de aula: dificuldades e possibilidades. Física na escola, v. 4, n. 1, p. 8-11, 2003.

SANTOS, A. O.; SILVA, R. P.; ANDRADE, D.; LIMA, J. Dificuldades e motivações de aprendizagem em química de alunos do ensino médio investigadas em ações do (pibid/ufs/química). Scientia plena, v. 9, n. 7, p. 1-6, 2013.

SANTOS, W. L. P. d. Educação científica na perspectiva de letramento como prática social: funções, princípios e desafios. Revista Brasileira de Educação, SciELO Brasil, v. 12, n. 36, p. 474-492, 2007.

SILVEIRA, M. P. d.; KIOURANIS, N. M. M. A música e o ensino de química. Química nova na escola, v. 28, n. 3, p. 28, 2008. 